\title{
A sucker for the job: morphology and functioning of suckers of polystomatid monogeneans
}

\author{
Louis Heyns Du Preez ${ }^{1,2}$ and Maxine Theunissen ${ }^{1}$
}

\author{
${ }^{1}$ Unit for Environmental Sciences and Management, North-West University, Potchefstroom Campus, Potchefstroom, South Africa; \\ ${ }^{2}$ South African Institute for Aquatic Biodiversity, Makhanda, South Africa
}

\begin{abstract}
Monogeneans rely on firm attachment to often flexible and uneven surfaces and are renowned for their effective posterior attachment structures in the form of adhesives, clamps, hamuli and suckers. Polystomatids do not secrete adhesives and do not have clamps. While only some have hamuli, all have suckers in the adult form. Three different types of haptoral suckers have been described based on basic morphology but have never been studied in depth. Using enzyme digestion and light (differential interference contrast), confocal and scanning electron microscopy, we examined representatives and propose four sucker types. Haptoral sucker Type I are symmetrical soft, flexible, cup- to disk-shaped suckers and are found in all polystomes infecting frogs and salamanders. Type II suckers are symmetrical soft, flexible, cup-shaped suckers with a hollow continuous skeletal ring and no other skeletal elements. They are found in species of Nanopolystoma Du Preez, Wilkinson et Huyse, 2008 infecting caecilians. Type III suckers are symmetrical firm, cup-shaped suckers with elaborate skeletal elements that contribute to a secure grip on the host tissue. This type of sucker is found in all polystomes infecting freshwater turtles and the common hippopotamus. Type IV suckers are asymmetrical with an elaborate series of long, thin sclerites with terminal spines or hooks. This type of sucker is only known from Concinnocotyla australensis (Reichenbach-Klinke, 1966) infecting the Australian lungfish. These different sucker types are crucial for the survival of polystomatid flatworms within their respective microhabitats.
\end{abstract}

Keywords: Polystomatidae, Monogenea, sclerite, morphology, haptoral sucker, type I, type II, type III, type IV

Adaptation is the key driving force for the survival of species. Species that do not adapt as a result of selective forces are more likely to perish (Combes 2005). Host switches by monogeneans from fish to other hosts are associated with a tendency to abandon the exposed ectoparasitic mode of life for an enclosed meso- or endoparasitic lifestyle. Poulin (2011) stated that an internal environment is, in general, more predictable than the external environment because all conspecific hosts are similar in general body plan and function, with organs performing the same function or secreting the same chemicals. Adaptations to these more predictable conditions are likely to spread to other members of the population. For example, any behaviour that increases the chance of arriving at the correct site of infection would be favoured (Poulin 2011). Some habitats, such as the nasal cavities, can still be considered external, while other habitats are truly internal, such as the oesophagus, stomach and urinary bladder (Euzet and Combes 1998). The posterior position of the haptor as seen in monogeneans enables freedom of the anterior end for feeding (Kearn 1994), and the nature of the substrate to which these parasites attach, along with water currents, play an important role in the adaptation of attachment organs and associated structures.
The peripheral arrangement of marginal hooklets around the cup-shaped haptor of the monogenean larval form, known as the oncomiracidium, provides a firm grip. However, few present-day adult monogeneans are small enough to be sustained by marginal hooks alone and this method of attachment only persists in the larval form. The general hypothesis is that the development of larger monogeneans and their survival on more active hosts led to the emergence of haptoral suckers and in some instances one or two pairs of larger hooks (hamuli), providing a more stable anchorage. This adaptation relates predominantly to morphological specialisation for posterior attachment by the haptor (Cribb et al. 2002) and the incorporation of suckers into the haptor was a significant advancement in the development of monogeneans (Kearn 1994).

Chisholm and Whittington (1998) demonstrated that the complexity of the haptor can be related to the habitat of the parasite. Parasites that live in habitats exposed to strong water currents, such as gills and dorsal skin surface, generally have more complex haptors compared with those that are subjected to less disturbed conditions (Euzet and Combes 1998). The biology of species of Polystoma Zeder, 1800 which infect the urinary bladder of anurans is an ex- 
cellent example of this transition. The presence of haptoral suckers is a characteristic that all polystomatid monogeneans share. While species of Sphyranura Wright, 1879 have only one pair of suckers, the remainder of the 30 genera all have three pairs of suckers.

Various authors have commented on variation in polystome haptoral sucker morphology (Stunkard 1917, Ozaki 1935, Sproston 1946, Williams 1960, Yamaguti 1963, Reichenbach-Klinke 1965, Kok and Du Preez 1989, Pichelin 1995, Du Preez and Kok 1998). Stunkard (1917) gave a detailed description of the suckers found in frog and turtle polystomes. He noted that the suckers are deeply embedded in the parenchyma of the haptor and are protrusible and retractile. Stunkard (1917) also noted that the sucker consists of three zones, namely basal, intermediate and external, with the external zone supported by numerous tegumental rods. He further stated that the intermediate band appears to be divided into sections that are almost square. Each section has a circular area in the centre and he speculated that the two sides of the invaginated tegumental sac or ring are fused at regular intervals, leaving small pockets alternating with the places of fusion. These small openings in the tegumental band are conspicuous by reason of their different refraction index. Pichelin (1995) agreed with this explanation offered by Stunkard (1917) and stated that this type of sucker attaches firmly to most surfaces, including glass and that no imprints are left on the host tissue. At the centre or basal region, Stunkard described a central disc or button to which the retractor muscles are attached.

Pichelin (1995) classified haptoral suckers of polystomes into three types. She described Type 1 suckers as simple muscular cups without sclerites, which are present in all the polystomes of anurans and salamanders. Polystomes of turtles as well as Oculotrema hippopotami Stunkard, 1924 from the hippopotamus were classified as having Type 2 suckers. These suckers were described as having a tegumental lining (Pichelin 1995). This tegumental lining projects into the side of the sucker cup to divide the musculature and create an inner equatorial groove (Pichelin 1995). Based on the yellowish colour, this author stated that the composition of the lining appeared to be soft keratin and that the projections can appear as circles in the equatorial groove on wholemounts. Pichelin (1995) hypothesised that the tegumental lining on the inside of the sucker may work with the musculature to attach to the host tissue and may provide more stability to the sucker. She also noted that the tegumental elements in the sucker appear to be more elaborate in the instance of $O$. hippopotami but the detail of these tegumental elements remained undescribed.

Du Preez et al. (2008) described Nanopolystoma Du Preez, Huyse et Wilkinson, 2008 from caecilian hosts and stated that they had skeletal support structures in the suckers which grouped them with chelonian polystomes, thus Type 2 suckers. Sucker skeletal elements have been reported or commented upon for chelonian polystome species of Polystomoides Ward, 1917 (see Du Preez and Van Rooyen 2015), Neopolystoma Price, 1939 (see Du Preez and Morrison 2012, Du Preez et al. 2017) and Oculotrema Stunkard,
1924 (see Moeng et al. 1998, Moeng and Du Preez 1999, Du Preez and Moeng 2004).

Skeletal elements inside haptoral suckers have also been reported for Concinnocotyla australensis (Reichenbach-Klinke, 1966). This species from the Australian lungfish, redescribed by Pichelin et al. (1991), has six cuplike bilaterally symmetric haptoral suckers with skeletal elements in the suckers. Suckers of $C$. australensis with a skeleton of sclerites and reduced musculature were referred to as a Type 3 sucker (Pichelin 1995).

Tinsley and Tinsley (2016) demonstrated that suckers of chelonian polystomatids from different sites in the host differ in relative size. The suckers of polystomatids found in the oral region are big and constitute the primary way of attachment, while those found in the urinary bladder rely more on the hamuli to provide a firm attachment to the bladder wall. Tinsley and Tinsley (2016) further pointed out that while the attachment organs of fish monogeneans have been well studied with detailed descriptions of morphological features (see Kearn and Evans-Gowing 1998, Kearn 2004), the haptor of polystomatids has never been investigated in depth for functionality. The present study focuses on haptoral sucker morphology and functionality, and proposes a new set of sucker types.

\section{MATERIAL AND METHODS}

Material used for the present study was collected over a period of 34 years or borrowed from museum collections. Techniques applied in the study included permanent, temporary, lactophenol or ammonium-picrate mounts, histological sectioning, enzyme digestion of soft tissue, scanning electron microscopy and confocal microscopy.

In order to study the harder skeletal structures in the suckers of species of Polystomoides, Neopolystoma and Oculotrema at the scanning electron microscopical (SEM) level, soft tissue was digested away using a Proteinase-K enzyme digestion technique adapted from Harris et al. (1999).

Specimens for SEM were dehydrated in an ethanol series, critical point dried, mounted, sputter-coated with gold palladium and examined with a FBI ESEM Quanta 200 scanning electron microscope or a Phenom desktop SEM. Methods for laser confocal microscopy by Yoon et al. (2013) and García-Vásquez et al. (2012) were followed in this study. For the illumination of F-actin and keratin in formalin-fixed specimens we used Alexa Fluor 488 phalloidin.

The present study is based on data from published papers and a study of permanent mounts and wet material. Material studied was borrowed from the National Museum, Bloemfontein, South Africa; Queensland Museum, Brisbane, Australia; and material from the collection of Louis du Preez (LDP). Specimens of Concinnocotyla australensis were photographed by Peter D. Olson at the Natural History Museum in London.

Specimens of Protopolystoma xenopodis (Price, 1943) were recovered from Xenopus laevis (Daudin), captured around the city of Potchefstroom, North-West Province, South Africa. Specimens of Polystoma australis Kok et van Wyk, 1986 were collected in 1994 from Semnodactylus wealii (Boulenger), at Ladybrand in the eastern Free State Province, South Africa. Specimens were fixed under coverslip pressure in $70 \% \mathrm{EtOH}$ or $10 \%$ neutral buff- 

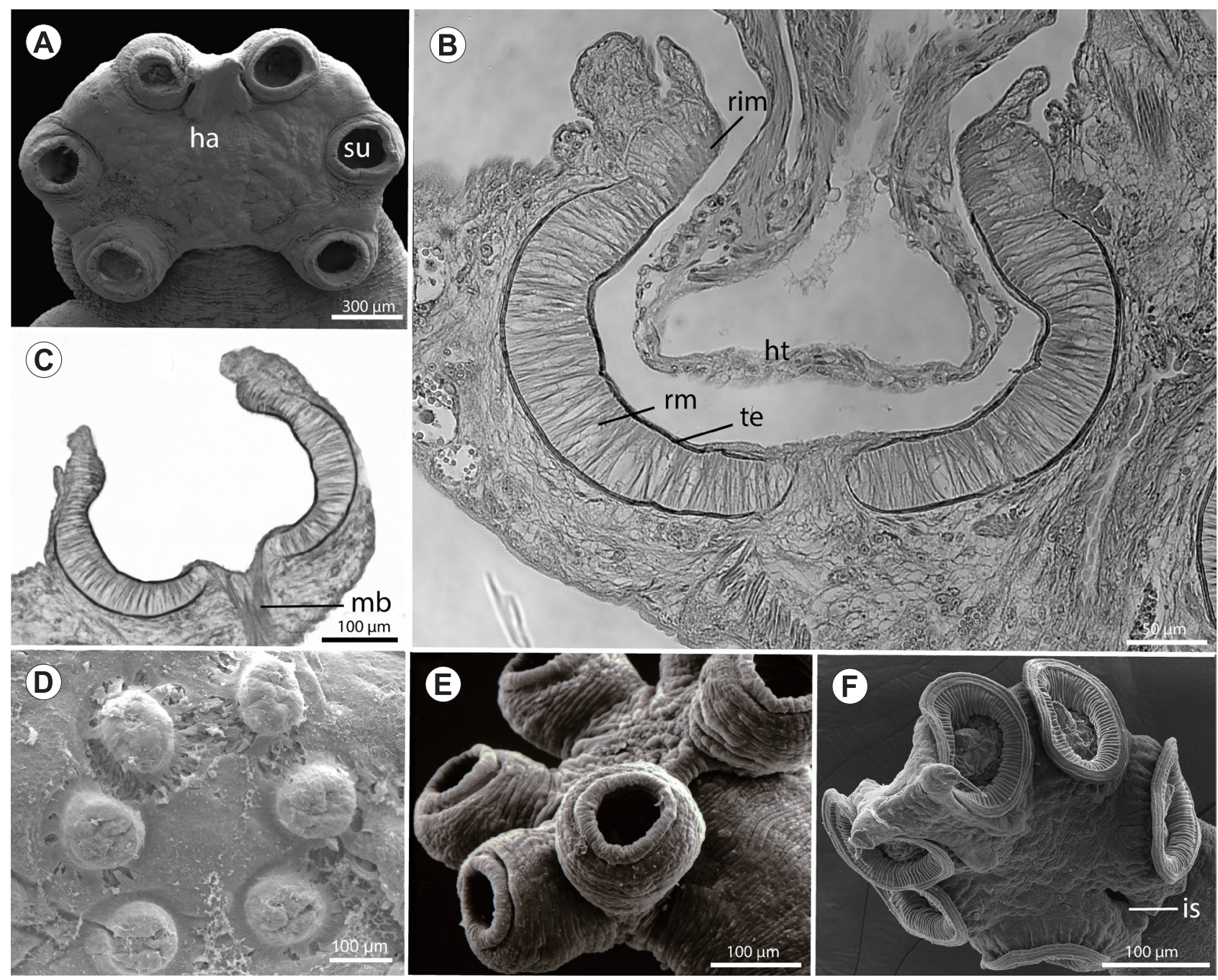

Fig. 1. Light and scanning electron micrograph images of Type I suckers. A - haptor of Polystoma australis Kok et van Wyk, 1986; B - sagittal section through an attached haptoral sucker of Polystoma claudecombesi Du Preez et Kok, 1995; C - sagittal section through a sucker of $P$. claudecombesi showing muscle bundles attached to the basal area of the sucker; $\mathbf{D}$-buds formed as host tissue is drawn inside the sucker cups; $\mathbf{E}$ - flexible suckers of the branchial morphotype of P. australis; $\mathbf{F}$ - haptor of Protopolystoma xenopodis (Price, 1943) showing the flattened, highly manoeuvrable suckers. Abbreviations: ha - hamulus; ht - host tissue; is - incision; mb muscle bundles; rim - ring muscle; rm - radial muscle fibres; su - sucker; te - tegument.

ered formalin. Specimens of the type series of Nanopolystoma brayii Du Preez, Huyse et Wilkinson, 2008, N. lynchi Du Preez, Huyse et Wilkinson, 2008 and N. tinsleyi Du Preez, Badets et Verneau, 2014, all from caecileans collected in Guiana and Brazil, were also studied. Type specimens were studied using light microscopy.

Specimens of Neopolystoma orbiculare (Stunkard, 1916) and Polystomoides sp. were collected from Trachemys scripta elegans (Wied) from the Fosseille River in Perpignan, France and those of $O$. hippopotami in the LDP collection were obtained from hippopotami culled in the Ndumo Game Reserve on the northern border of KwaZulu-Natal Province, South Africa (Du Preez and Moeng 2004).

\section{RESULTS}

\section{Haptoral sucker Type I}

Sucker Type I corresponds to Type 1 of Pichelin (1995). All genera from anuran and urodelid hosts (Table 1) have
Type I suckers. These suckers are simple symmetrically muscular and cup-shaped, without any skeletal support elements embedded in the sucker wall. Suckers of species of Polystoma are flexible to firm and the opening is directed ventrally (Fig. 1A) and made up of a series of muscles. Sucker cups are lined inside and outside by a tegument with a series of radial muscle fibres in-between (Fig. 1B). Distally along the inner periphery of the sucker, a bundle of muscles forms a ring around the opening (Fig. 1B). At the base of each sucker a disk of connective tissue is attached to several strong bundles of muscular fibres (Fig. 1C). When a parasite that had been fixed in situ was pulled free of the host tissue, the six dome shaped protrusions were clearly visible (Fig. 1D). The marginal hooklet at the base of each sucker is embedded in the parenchyma, and on none of several serial sections of suckers attached to host tissue we found evidence that these hooks may hook onto the host tissue.

Species of Polystoma and Metapolystoma Combes, 1976 have branchial phases whereby the infective larvae 

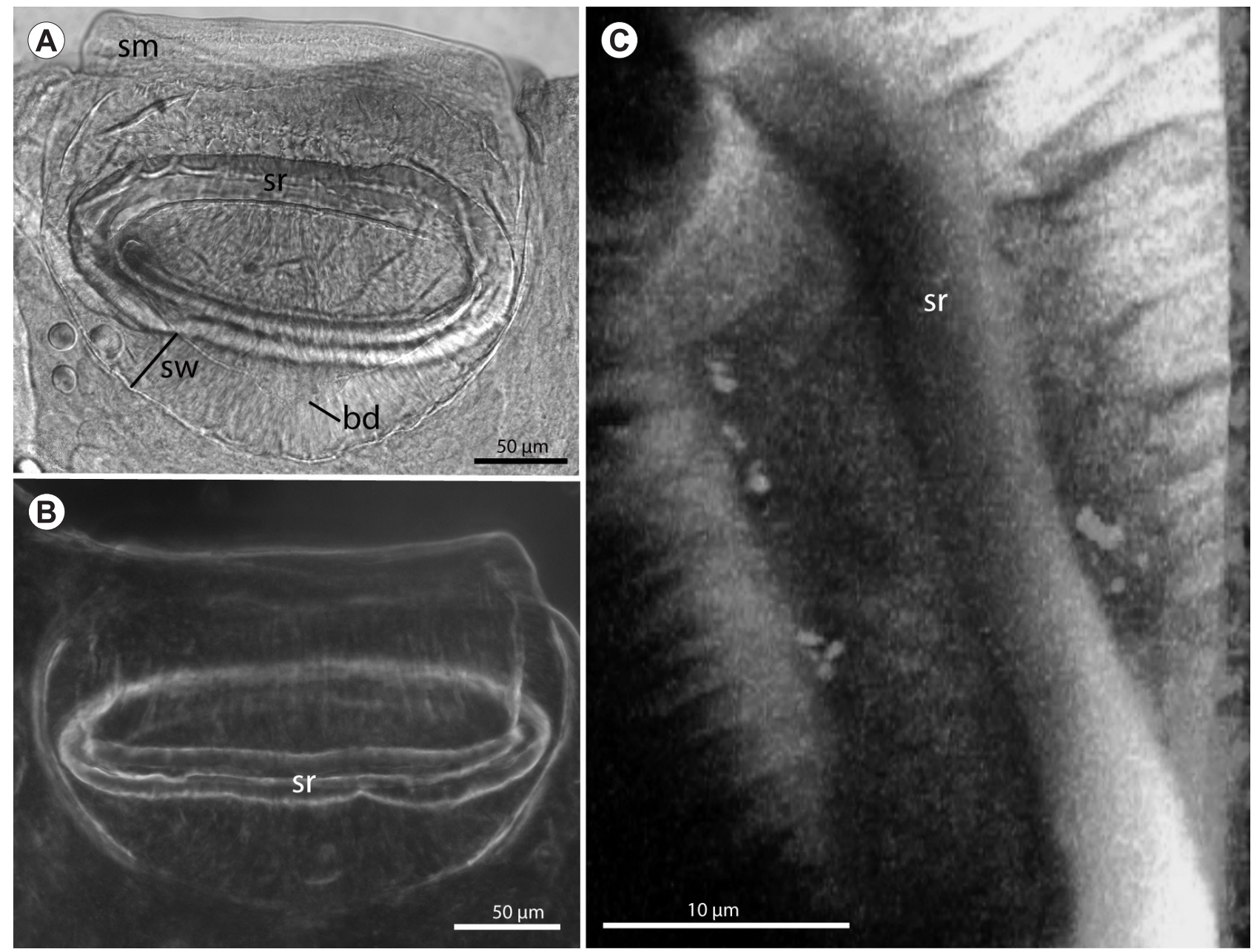

Fig. 2. Light and confocal scanning laser micrograph images of Type II suckers. A - light micrograph of the haptoral sucker of Nanopolystoma tinsleyi Du Preez, Badets et Verneau, 2014 mounted in lactophenol; B - stacked focused image using differential interference contrast micrograph of the sucker of $N$. tinsleyi mounted in lactophenol; $\mathbf{C}$ - confocal image of the autofluorescing skeletal ring of Nanopolystoma brayii Du Preez, Huyse et Wilkinson, 2008. Abbreviations: bd - basal depression; sm - sucker rim; sr - skeletal ring; sw - sucker wall.

enter the gill chamber of the host species tadpole and follow a paedomorphic reproductive strategy. Parasites develop rapidly to secure a firm grip on the gills within the gill-chamber through which water is constantly flushed. Initially, attachment is secured by the 16 marginal hooklets but as the parasite rapidly develops, the marginal hooklets are replaced by six flexible suckers (Fig. 1E).

In species of Protopolystoma Bychowsky, 1957, suckers are flattened disks and directed ventrolaterally (Fig. 1F) and with a very soft flexible haptor. Along the anterior margin of the haptor an incision (Fig. 1F) adds to the manouverability of the haptor. Suckers are very flexible and the sucker-wall is quite narrow. When a parasite is removed from the host tissue suckers will double over and attach to other suckers or to the body of the parasite. These suckers provide a very firm and secure attachment and the thin and soft urinary bladder lining is effectively sucked into the sucker cups. The moment a sucker detaches, the bladder tissue straightens and no damage is caused to the bladder lining. When a frog bladder containing polystomes is cut open in a Petri dish, a parasite can easily be dislodged by inserting the tip of a brush under the attached haptor. In the instance of Protopolystoma spp. and branchial forms of Polystoma or Metapolystoma, the haptors and suckers are extremely flexible and the parasite will readily double over and attach to itself.

\section{Haptoral sucker Type II}

These suckers are soft, simple symmetrically couldron-shaped suckers with the opening directed ventrally (Fig. 2A,B), very similar to Type I suckers. The periphery of the sucker opening or rim is prominent (Fig. 2A) and contains a ring of muscle fibres. The sucker wall is thick (Fig. 2A) with densely packed muscle fibres. Light microscopy revealed a prominent chitinous ring in the middle of the suckers of all species of Nanopolystoma (Fig. 2A,B). Confocal microscopy revealed that this skeletal ring is continuous and autofluorescing (Fig. 2C). The ring is hollow and resembles a pipe (Fig. 2A-C). At the base of the sucker there is a depression (Fig. 2A). Bundles of muscles from deeper layer in the haptor are attached to the base of the suckers. Specimens attached to the bladder wall were easily dislodged using a camel hair brush. 

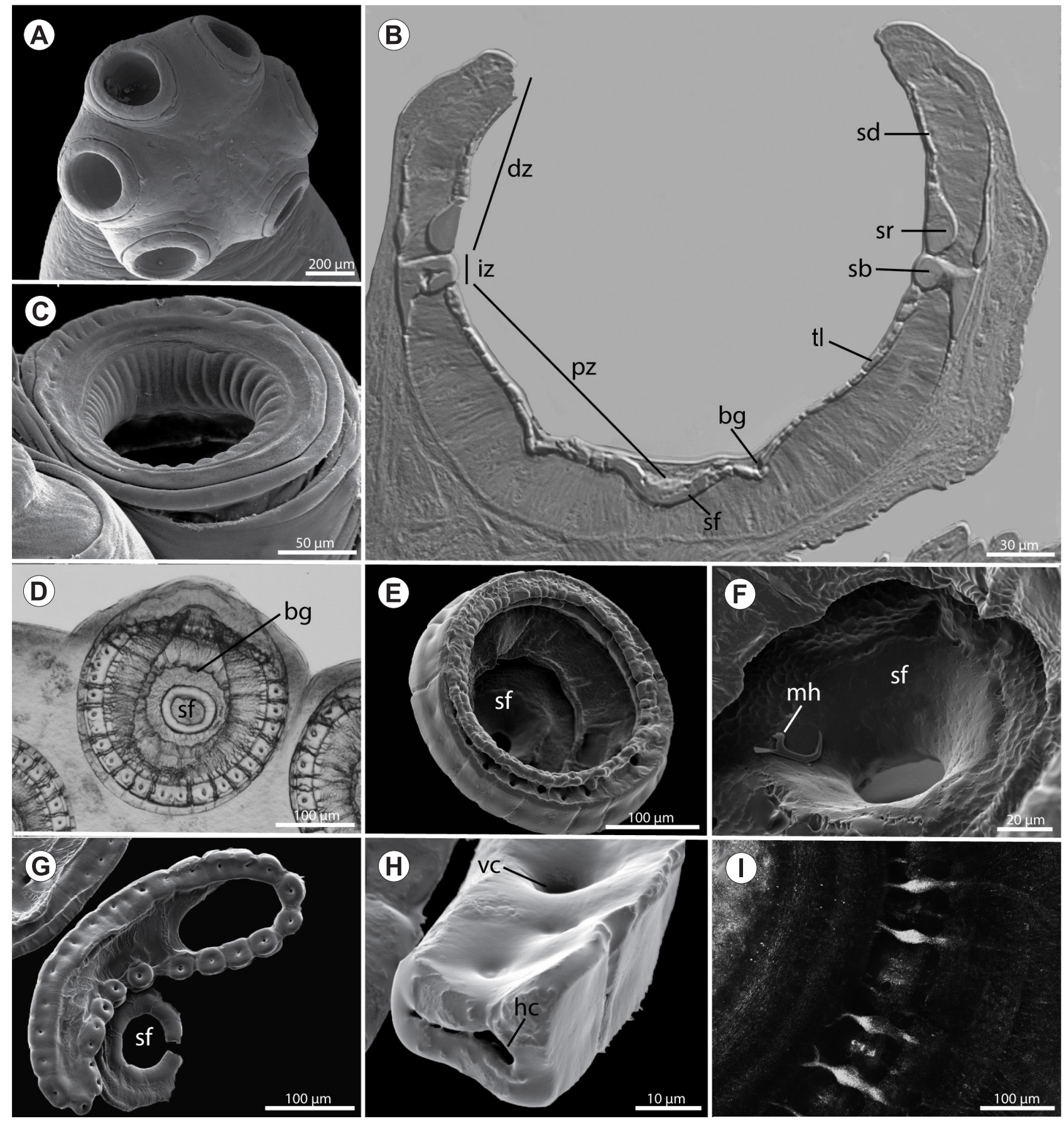

Fig. 3. Light, scanning electron and confocal scanning laser micrograph images of Type III suckers. A - haptor of Neopolystoma sp.; B - sagittal section through a haptoral sucker of Neopolystoma liewi Du Preez et Lim, 2000; C - haptoral sucker of N. liewi; D - lactophenol cleared sucker of $N$. liewi; $\mathbf{E}$ - partially digested sucker of Polystomoides sp.; $\mathbf{F}$ - partially digested sucker of Polystomoides sp. showing the skeletal funnel and marginal hooklet; $\mathbf{G}$ - partially digested sucker of $N$. liewi showing the skeletal funnel and indivudual skeletal blocks; $\mathbf{H}$ - indivudual skeletal blocks of $N$. liewi; $\mathbf{I}$ - close up of the sucker of Polystomoides sp. showing muscle fibres running through the canals in the skeletal blocks following staining with Alexa Fluor. Abbreviations: bg - basal groove; $t$ - tegumental lining; $\mathrm{dz}$ - distal zone; hc - horizontal canal; iz - intermediate zone; $\mathrm{mh}$ - marginal hooklet; $\mathrm{pz}$ - proximal zone; sb - skeletal block; sd - skeletal digiti; sf - skeletal funnel; sr - skeletal ring; vc - vertical canal.

\section{Haptoral sucker Type III}

Sucker Type III corresponds to Type 2 of Pichelin (1995). All polystomes infecting chelonian hosts have Type III suckers (Table 1). These suckers are spherical, symmetrical, firm, directed ventrolaterally (Fig. 3A) and characterised by having embedded skeletal elements that provide a secure grip on the host tissue (Fig. 3B,C). These skeletal elements are visible as a ring of blocks or sometimes appear to be rounded (Fig. 3D).

Haptoral suckers of species of Apaloneotrema Du Preez et Verneau, 2020, Aussietrema Du Preez et Verneau, 2020, Fornixtrema Du Preez et Verneau, 2020, Neopolystoma, Polystomoidella Price, 1939, Polystomoides and Oculotrema that were studied are supported by a complex skele- 

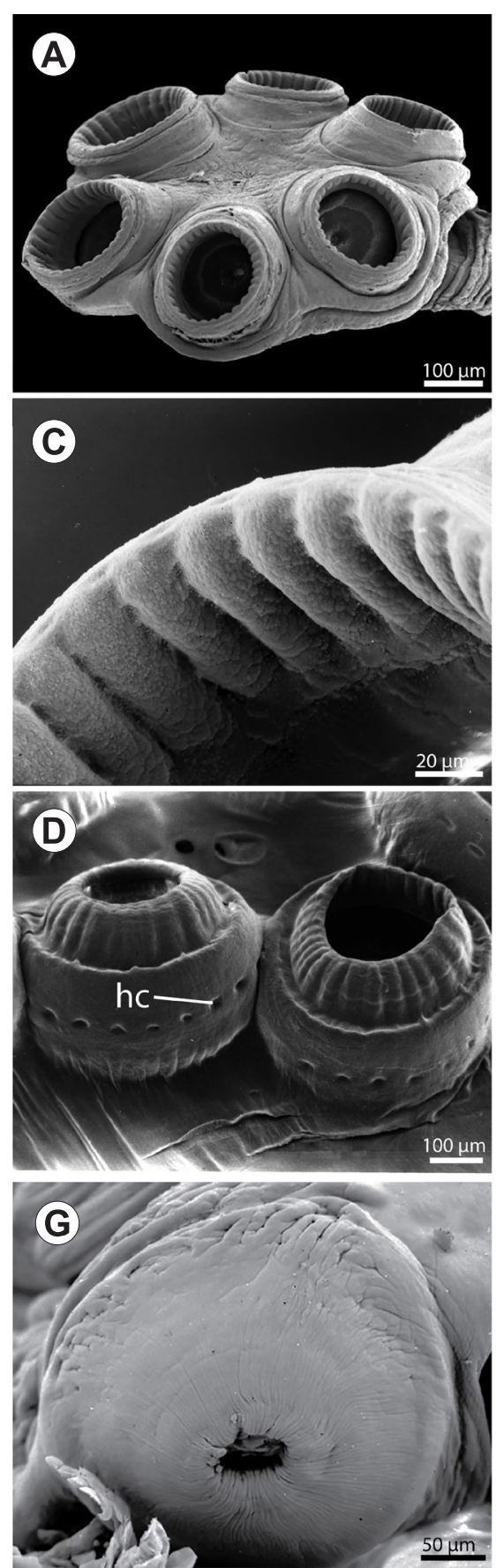

(B)

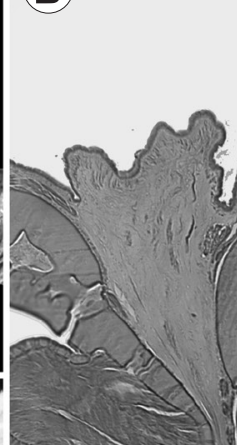

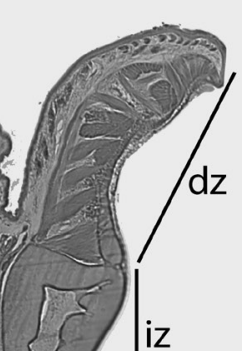
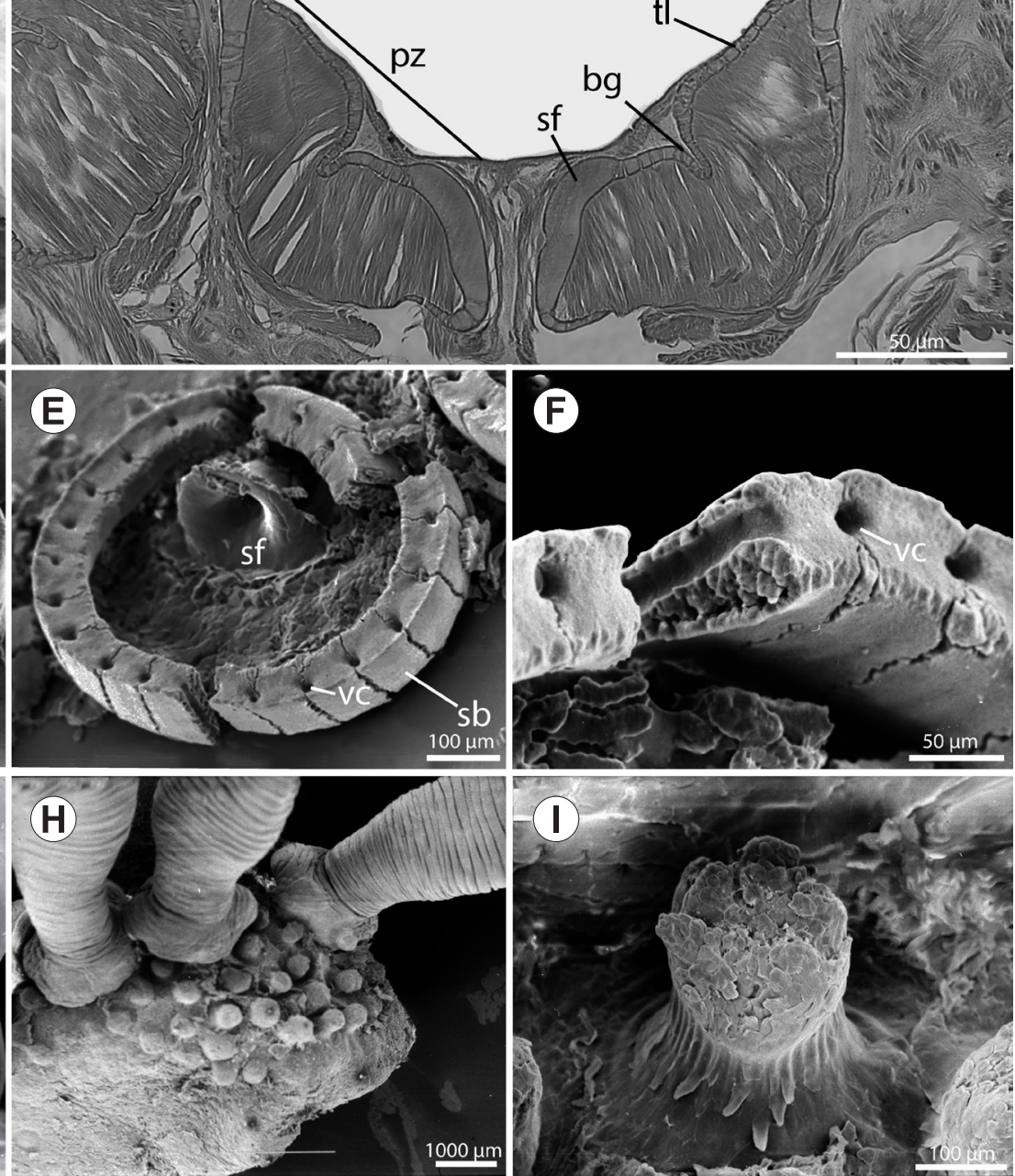

Fig. 4. Light and scanning electron micrograph images of Type 2 suckers for Oculotrema hippopotami Stunkard, 1924. A - haptor; B - sagittal section through a haptoral sucker; C - haptoral sucker wall; D - partially digested sucker; $\mathbf{E}$ - skeletal elements following enzyme digestion of soft tissues; $\mathbf{F}$ - skeletal blocks showing the setated joints between blocks and the vertical canals; $\mathbf{G}$ - contracted sucker; $\mathbf{H}$ - cluster of parasites on the eye of a hippopotamus; $\mathbf{I}$ - a single host tissue protrusion where a sucker was attached. Abbreviations: bg - basal groove; $\mathrm{tl}$ - tegumental lining; $\mathrm{dz}$ - distal zone; hc - horizontal canal; iz - intermediate zone; $\mathrm{pz}$ - proximal zone; $\mathrm{sb}$ - skeletal block; sd - skeletal digiti; sf - skeletal funnal; sr - skeletal ring; vc - vertical canal.

tal structure. Based on the morphology of the skeletal elements, the Type III sucker can be divided into three zones, namely the proximal zone (pz), intermediate zone (iz) and distal zone (dz) (Fig. 3B). The complete inner surface of the funnel is lined with skeletal elements. The proximal zone is the area deep in the sucker and consists of a firm skeletal funnel (Fig. 3D-F) and a thin tegumental lining that extends to the intermediate zone. A short distance from the funnel, this tegumental lining folds outward onto the side of the sucker to form a basal groove that appears as a ring around the funnel (Fig. 3B,D,E). The tegumental lining is not a solid structure but consists of small segments that provide flexibility. Attached to the funnel are several bundles of muscles leading deeper into the haptor. This funnel is shallow in species of Apaloneotrema, Fornixtrema, Nanopolystoma, Neopolystoma, Polystomoidella and Polystomoides to deeper than wide in the case of species of Aussietrema and Oculotrema. 

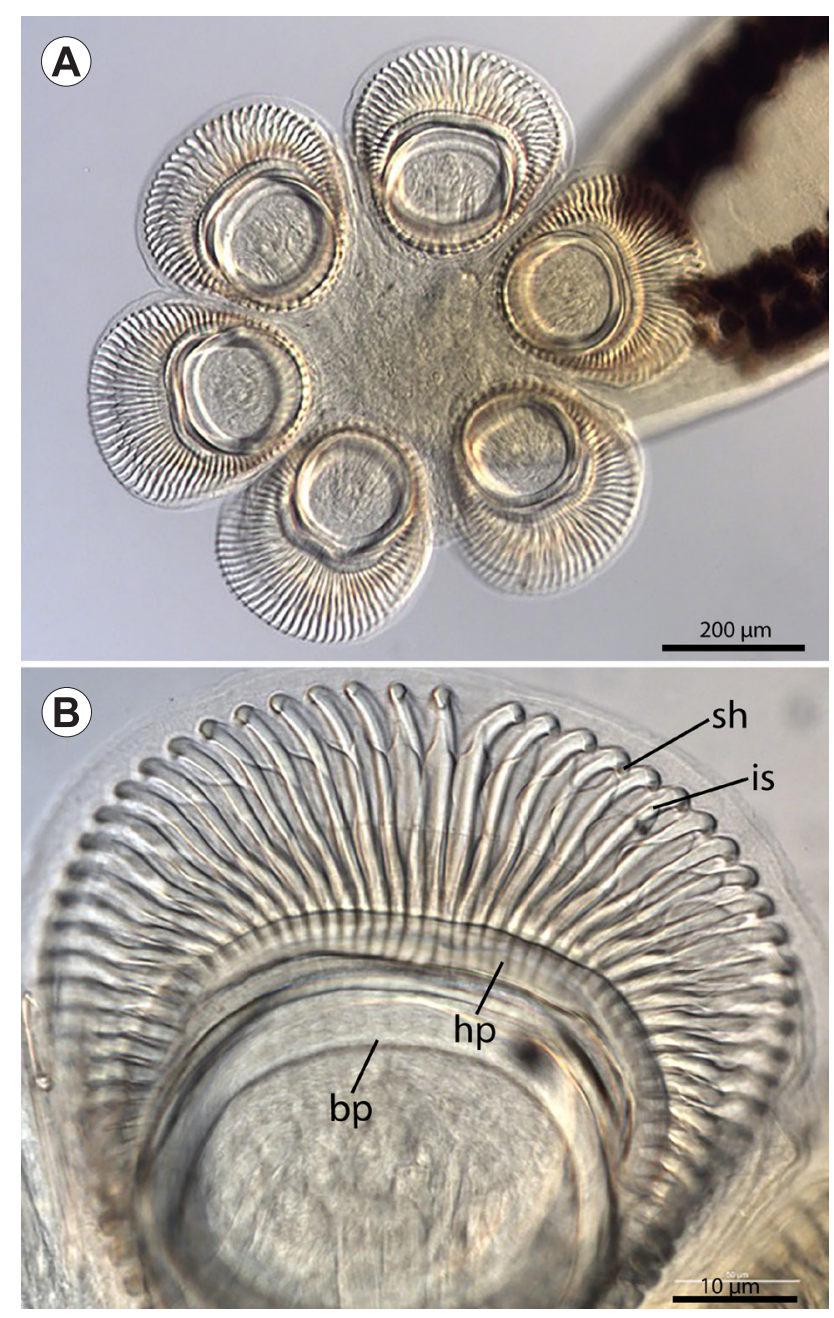

Fig. 5. Light micrographs of haptoral suckers of Concinnocotyla australensis (Reichenbach-Klinke, 1966). Abbreviations: bp basal plate; hp - half-circle plate; is - inner spatulate sclerite; sh - sclerite with hook. Courtesy of Peter D. Olson, Natural History Museum, London.

The second zone, also known as the intermediate zone, is not situated in the middle of the sucker but more towards the opening, resulting in the peripheral zone being twice the size of the distal cone (Fig. 3B). The key element of the intermediate zone is a ring of interconnected skeletal blocks resembling an in-line bracelet in all chelonian polystomes as well as in $O$. hippopotami. Along the inside on both sides of the skeletal ring are sclerite support rings with the outer ring bigger than the inner (Fig. 3B). Partial enzyme digestion of suckers revealed that in species of Polystomoides (Fig. 3D) and Neopolystoma (Fig. 3G,H) the blocks of the interconnected skeletal ring have slightly rounded edges and corners, and through the middle of each run a vertical canal and a horizontal canal (Fig. 3H) about 4-5 $\mu \mathrm{m}$ in diameter. Confocal laser scanning microscopy of the haptor of a specimen of Polystomoides sp. labelled for f-actin with Alexa Fluor 488 that stains for actin confirmed the hypothesis that muscle bundles run through the canals in the skeletal blocks (Fig. 3I).

Skeletal chitinous digiti or tegumental rods extend in the distal zone from the outer support ring along the in- side as well as the outside of the sucker wall with the inner rods extending nearly to the periphery of the sucker opening (Fig. 3B), whereas the outer rods are more delicate and shorter. These inner rods give the distal zone the appearance of longitudinal ridges (Fig. 3B). In the case of $O$. hippopotami, the suckers are oriented slightly outward (Fig. 4A), the skeletal elements are more pronounced (Fig. 4B) and the longitudinal ridges in the distal zone are very prominent (Fig. 4C,D). Partial enzyme digestion of suckers of $O$. hippopotami revealed that these skeletal blocks are deeper, more robust and, based on the reaction of the enzyme, harder, with sharp edges (Fig. 4E,F), serrated interlocking fissures (Fig. 4F), a vertical canal with a diameter of $15 \mu \mathrm{m}$, not through each block but between two adjacent blocks (Fig. 4E,F), and with a horizontal canal from the inside of the ring to the outside underneath each block (Fig. 4D). The skeletal funnel in the basal zone is a firm structure with an inner and an outer chitinous rim and is as deep as it is wide (Fig. 4B,E).

Sucker openings can close almost completely (Fig. 4G). Conjunctival sac polystomes (Apaloneotrema, Fornixtrema and Oculotrema), usually form tight clusters (Fig. $4 \mathrm{H})$ where they stay attached and stretch out to feed on the surface of the eye and conjunctival sack. This attachment is so firm that it is very difficult to pull an attached parasite free. A specimen of $O$. hippopotami was fixed in situ on the host tissue and then pulled off to illustrate to what extent the skeletal ring clamps down on the host tissue creating epithelial buds (Fig. 4H,I). Imprints made by the chitonous digiti in the distal zone of the sucker around the neck of the host tissue protrusion (Fig. 4I) document the very secure grip of Oculotrema. In order to dislodge a firmly attached $O$. hippopotami in situ a blunt dissecting needle and some force is required to dislodge the suckers.

\section{Haptoral sucker Type IV}

Sucker Type IV corresponds to Type 3 of Pichelin (1995). Concinnocotyla australensis is the only polystome known to date with sucker Type IV (Table 1). This asymmetrical sucker (Fig. 5A) has an elaborate skeleton of sclerites with a ring-shaped thick basal plate in the middle and a second half-circle plate to the outside (Fig. 5B). From the ring, two rows of thin sclerites are arranged in the shape of a fan (Fig. 5B). The inner set of sclerites is flattened, spatulate and, at the distal ends, tapers sharply to an acute tip. The outer set has long, densely packed, needle-like sclerites with sharp downward-facing sharp hooks at the distal ends (Fig. 5B).

\section{Remarks on the mechanism of sucker funtioning}

For sucker Type I we hypothesise that when the sucker is pressed against the host tissue, the muscles attached to the base of the sucker contract and draw back the bottom of the sucker, creating a vacuum that sucks the soft urinary bladder tissue into the sucker. The ring of muscles along the periphery contracts, locking host tissue in the cavity and securing an effective grip. When a parasite is removed from its site of attachment, the host tissue straightens immediately without leaving any scars. The marginal hooklet at the base 
Table 1. List of polystomatid genera with an indication of sucker type

\begin{tabular}{|c|c|c|}
\hline Genus & Host group & $\begin{array}{c}\text { Sucker } \\
\text { type }\end{array}$ \\
\hline Diplorchis Ozaki, 1931 & Anura & I \\
\hline Eupolystoma Kaw, 1950 & Anura & I \\
\hline Indopolystoma Chaabane, Verneau et Du Preez, 2019 & Anura & I \\
\hline $\begin{array}{l}\text { Kankana Raharivolololniaina, Verneau, Berthier, } \\
\text { Vences et Du Preez, } 2011\end{array}$ & Anura & I \\
\hline $\begin{array}{l}\text { Madapolystoma Du Preez, Raharivolololniaina, } \\
\text { Verneau et Vences, } 2010\end{array}$ & Anura & I \\
\hline Mesopolystoma Vaucher, 1981 & Anura & I \\
\hline Metapolystoma Combes, 1976 & Anura & I \\
\hline Neodiplorchis Yamaguti, 1963 & Anura & I \\
\hline Neoriojatrema Imkongwapang et Tandon, 2010 & Anura & I \\
\hline Parapolystoma Ozaki, 1935 & Anura & I \\
\hline Parapseudopolystoma Nasir et Fuentes Zambrano, 1983 & Anura & I \\
\hline Polystoma Zeder, 1800 & Anura & I \\
\hline Protopolystoma Bychowsky, 1957 & Anura & I \\
\hline Pseudodiplorchis Yamaguti, 1963 & Anura & I \\
\hline Riojatrema Lamothe-Argumedo, 1964 & Anura & I \\
\hline Sundapolystoma Lim et Du Preez, 2001 & Anura & I \\
\hline Wetapolystoma Gray, 1983 & Anura & I \\
\hline Pseudopolystoma Yamaguti, 1963 & Caudata & I \\
\hline Sphyranura Wright, 1879 & Caudata & I \\
\hline Nanopolystoma Du Preez, Wilkinson et Huyse, 2 & $\begin{array}{l}\text { Gymno- } \\
\text { phiona }\end{array}$ & II \\
\hline Apaloneotrema Du Preez et Verneau, 2020 & Chelonia & III \\
\hline Aussietrema Du Preez et Verneau, 2020 & Chelonia & III \\
\hline Fornixtrema Du Preez et Verneau, 2020 & Chelonia & III \\
\hline Neopolystoma Price, 1939 & Chelonia & III \\
\hline Polystomoidella Price, 1939 & Chelonia & III \\
\hline Polystomoides Ward, 1917 & Chelonia & III \\
\hline Uropolystomoides Tinsley et Tinsley, 2016 & Chelonia & III \\
\hline Uteropolystomoides Tinsley, 2017 & Chelonia & III \\
\hline Oculotrema Stunkard, 1924 & Mammalia & III \\
\hline Concinnocotyla Pichelin, Whittington et Pearson, 19 & Dipnoi & IV \\
\hline
\end{tabular}

of each sucker is embedded in the parenchyma, and on none of several serial sections of suckers attached to host tissue evidence was found that these hooks may hook onto the host tissue. The flexibility of the branchial phases of species of Polystoma and Metapolystoma is an important morphological adaptation as the parasites often have to attach to the delicate gill filaments of two neighbouring gill arches.

Based on the morphology of Type II suckers, we hypothesise that, as for Type I sucker, the sucker is pressed against the host tissue, the muscles attached to the base of the sucker contract and draw back the bottom of the sucker, creating a vacuum that sucks the soft host tissue through the skeletal loop into the sucker. The ring muscle around the opening contracts to clamp on the host tissue. No indication could be found that the skeletal loop can contract.

Type III suckers with their elaborate skeletal elements provide a more complex mode of attachment. We hypothesise that during attachment suckers are pressed firmly against the host tissue with the basal groove providing the required flexibility. The muscles running through the skeletal ring relax. Muscles attached to the skeletal funnel contracts and the skeletal funnel at the base of the sucker is pulled back creating a vacuum within the sucker. Host tissue is drawn into the sucker. Longitudinal muscles contract throughout the sucker, together with the muscles running through the skeletal ring and a ring of muscle fibres along the outer periphery of the sucker, which results in the skel- etal ring clamping around the host tissue and the mouth of the sucker closes tightly around the protrusion of host tissue, ensuring a very firm grip.

For Type IV suckers no histological sections were available and we can only speculate about the functional mechanism of this sucker type. The skeletal ring is most likely equivalent to the skeletal funnel of the Type III sucker and provides a firm structure for muscle attachment, closely corresponding with the half-circle ring. Two sets of thin radial sclerites fan out from the half-circle ring. We hypothesise that the sucker is pressed flush against the host tissue. When the skeletal ring is pulled back by contracting muscles, the sucker opening would tighten and terminal hooks of the radial ring of sclerites would slam into the host tissue providing a secure grip. Each sucker thus serves as an anchor.

\section{DISCUSSION}

Parallel with their hosts, monogeneans infecting internal sites had to go through a series of adaptation events. These include the loss of habitat (gills) due to anuran hosts undergoing metamorphosis, drying of skin as frogs leave the aquatic environment, and interrupted transmission opportunities as frogs would only frequent water bodies intermittently. Parasites that have successfully radiated to internal sites of their host are still faced with numerous challenges.

The urinary bladder is a delicate and highly elastic structure that stretches extensively as the bladder fills with urine or water when the host enters an aquatic environment resulting in fluctuating levels of salinity. When entering aquatic environments, frogs hydrate and, as the urinary bladder fills, they tend to urinate more frequently with a reduction in salinity of the urine. When hibernating, the salinity inside the bladder gradually increases, putting parasites under increased osmotic stress. The thin contractile membrane of the bladder undergoes sporadic changes in the surface area and thickness, so that the haptor of the parasite should be able readily to detach and reattach (Tinsley 1971).

In the oral region of turtles, parasites attach in the nasal passages, palate or the mucosa of the pharyngeal pouch. Although they attach to a much firmer structure than the urinary or accessory bladders, oral parasites are constantly dealing with the threat of being mechanically dislodged when turtles are feeding and a firm attachment is thus paramount to their survival. Parasites in the conjunctival sac of the turtle's eye or on the eye of the hippopotamus are attached to a firm structure but face the threat of being dislodged during eye blinking or when water flushes over the eye. When turtles and hippopotami swim underwater, they do so with open eyes and parasites would thus be exposed to some degree of water flushing over the eye. Likewise Concinnocotyla australensis, which attaches to the oral mucosa or the gills of the Australian lungfish (Pichelin et al. 1991), is exposed to gill-ventilation currents and thus also requires a firm attachment.

All sites where polystomes are found pose some challenges and the ways in which they have managed to adapt to these microhabitats are key to their survival and evolutionary change over hundreds of millions of years. As pointed out by Tinsley and Tinsley (2016), species of Uropolysto- 
moides Tinsley et Tinsley, 2016 found in the urinary bladder of turtles have relatively small suckers but large hamuli whereas species of Polystomoides from the oral region have small hamuli but large suckers. Polystomes from the ocular region have the ability to stretch out and nearly double their body length (Du Preez and Verneau 2020) and as a result do not have to wander around in search of food. These parasites are often found in clusters (Fig. 3H).

Marginal hooklets reach their final size before the oncomiracidium emerges from the egg and persist without any further growth (Tinsley and Tinsley 2016). When they are replaced by haptoral suckers and hamuli as primary attachment organs they do not disappear as has been claimed by some authors (Ozaki 1935). Marginal hooklet pairs 1 and 2 are retained posteriorly between sucker pair 1; marginal hooklets 3, 4 and 5 are found at the base of each sucker (Fig. 2F), and marginal hooklet pairs 6, 7 and 8 are found anterior in the haptor between sucker pair 3 . These marginal hooklets are embedded in the parenchyma. Tinsley and Tinsley (2016) claim that the marginal hooklets inside the suckers hook onto the host tissue and impale the enclosed bladder tissue but these authors fail to provide any evidence for this claim. Several sets of serial sections through suckers attached to host tissue were carefully examined but we could not find any evidence that marginal hooklets assist with attachment of adult polystomes.

Polystomes of anuran and urodelid hosts rely on the musculature of the suckers to secure a firm grip on the soft and contractile host tissue without the aid of skeletal elements in the suckers. A plug of host tissue is pulled into the dome of the sucker where it is gripped by the muscles surrounding the sucker opening. The majority of anuran polystomes have hamuli that assist in securing a firm grip. Polystomes of the genus Sphyranura from urodelid hosts also posess hamuli, whereas species of Pseudopolystoma Yamaguti, 1963 lack hamuli. Whereas Pseudopolystoma is well nested within anuran polystomes, Sphyranura occupies a basal position to the bigger Anura-urodelid polystome clade (Héritier et al. 2015).

Species of Nanopolystoma infecting caecilians cluster with polystomes infecting chelonian hosts as well as Oculotrema, infecting a mammalian host (Héritier et al. 2015). With Nanopolystoma occupying a basal position in this clade, Héritier et al. (2015) speculated that because primitive amniotes were mostly terrestrial, the lineage of turtle polystomes could have coevolved with Nanopolysto$m a$. The presence of skeletal elements in the suckers of all polystomes of this clade provides further supporting evidence.

Monogeneans are renowned for their firm attachment but within the Polystomatidae and between the four different types of suckers there is a marked difference in the attachment. This is determined by the attachment mechanism as described for each sucker type, and also by the nature of the site where the parasite is found. Parasites with Type I suckers, such as the polystomes infecting frogs and salamanders, can easily be detached using a fine brush. The same is true for species of Nanopolystoma infecting cecil- ians (Type II suckers) where they are found in the urinary bladder and phallodeum of caecilians.

Chelonian polystomes (Type III) infecting the bladder can be detached with a brush but a blunt needle is required to detatch those infecting the oral region and conjunctival sacs. For C. australensis, as representative of Type IV suckers, the authors have no firsthand experience and Pichelin et al. (1991) merely stated that the "opercula, gills and upper and lower jaws were removed, placed separately in vessels containing aged water" and that parasites were removed and placed in a container with aged water. Judging from the array of hooked sclerites, one can assume a firm attachment.

Of the 30 known polystome genera only Polystoma and Metapolystoma, infecting frogs, have a branchial form on the gills of tadpoles of the host species (Du Preez and Kok 1992). Although genetically identical, the branchial morphotype differs markedly from the mature bladder morphotype. In contrast to the mature bladder morphotype, the branchial morphotype has no hamuli, no vaginae, an elongated enlarged ovary and a haptor with six flexible and highly maneuverable suckers. Although Williams (1960) stated that the suckers and associated muscles resemble those of the bladder morphotype, there are marked differences. Suckers can maneuver independently and tilt to attach in a lateral direction. Following contact with a host tadpole the oncomiracidium exercises a choice of development based on the physiological age of the tadpole. If the tadpole is still small and in pre-metamorphosis, the oncomiracidium attaches to the branchial filaments, loses its cilia and starts feeding on blood. This parasite develops rapidly and within 16 days it is a fully formed egg-producing parasite. If the oncomiracidium infects a tadpole in pro-metamorphosis, usually indicated when the developing hind limb is no longer a straight bud but bends at the knee, the oncomiracidium will enter the branchial chamber via the sinistral spiracle, attach to the gill filaments, and start feeding whilst developing slowly. The hamulus primordia start to enlarge and when the front legs of the tadpole, which develop inside the branchial chamber, break out, the young bladder-destined parasite will crawl out and migrate over the abdomen of the metamorphosing tadpole and enter the cloaca where it will attach to the bladder wall and continue to develop (Kok and Du Preez 1987). The destination of the parasite (gills or bladder) determines the morphotype and the type of haptor and suckers (rigid in bladder parasites or flexible and soft in branchial parasites).

Acknowledgements. This study was finantially supported by the National Research Foundation of South Africa. The Queensland Museum, Brisbane, Australia and the National Museum, Bloemfontein, South Africa lent material. The Unit for Environmental Science and Development, North-West University, South Africa, provided a travel grant to Maxine Theunissen to conduct field work in France. Thanks are due to Olivier Verneau for providing accommodation and for assistance during fieldwork in Perpignan, France, Itumeleng Moeng for assistance with the collection of Oculotrema hippopotami and processing of material, and Vincent and Jane Carruthers and Les Minter for commenting on the manuscript. Two anonymous reviewers and the editor provided helpful comments. 


\section{REFERENCES}

Chisholm L.A., Whittington I.D. 1998: Morphology and development of the haptors among the Monocotylidae (Monogenea). Hydrobiologia 383: 251-261.

Combes C. 2005: The Art of Being a Parasite, University of Chicago Press, Chicago, $291 \mathrm{pp}$.

Cribb T.H., Chisholm L.A., Bray R.A. 2002: Diversity in the Monogenea and Digenea: does lifestyle matter? Int. J. Parasitol. 32: 321-328.

Du Preez L.H., Badets M., Héritier L., Verneau O. 2017 Tracking platyhelminth parasite diversity from freshwater turtles in French Guiana: first report of Neopolystoma Price, 1939 (Monogenea: Polystomatidae) with the description of three new species. Parasit. Vector. 10: 53.

Du Preez L.H., KoK D.J. 1992: Syntopic occurrence of new species of Polystoma and Metapolystoma (Monogenea: Polystomatidae) in Ptychadena porosissima in South Africa. Syst. Parasitol. 22: 141-150.

Du Preez L.H., KoK D.J. 1998: The relative importance of bladder versus neotenic stages of Polystoma marmorati and $P$. umthakathi in natural frog populations in South Africa. J. Helminthol. 72: 117-121.

Du Preez L.H., Moeng I.A. 2004: Additional morphological information on Oculotrema hippopotami Stunkard, 1924 (Monogenea: Polystomatidae) parasitic on the African hippopotamus. Afr. Zool. 39: 225-233.

Du Preez L.H., Morrison C. 2012: Two new polystomes (Monogenea: Polystomatidae) from the eyes of North American freshwater turtles. Zootaxa 3392: 47-59.

Du Preez L.H., VAN Rooyen M. 2015: A new polystomatid (Monogenea: Polystomatidae) from the mouth of the North American freshwater turtle Pseudemys nelsoni. ZooKeys 539: 1-9.

Du Preez L.H., Verneau O. 2020: Eye to eye: classification of conjunctival sac polystomes (Monogenea: Polystomatidae) revisited with the description of three new genera Apaloneotrema n. g., Aussietrema n. g. and Fornixtrema n. g. Parasitol. Res. 119 4017-4031

Du Preez L.H., Wilkinson M., Huyse T. 2008: The first record of polystomes (Monogenea: Polystomatidae) from caecilian hosts (Amphibia: Gymnophiona) with the description of a new genus and two new species. Syst. Parasitol. 69: 201-209.

Euzet L., Combes C. 1998: The selection of habitats among the Monogenea. Int. J. Parasitol. 28: 1645-1652.

García-VÁsquez A., Shinn A.P., Bron J.E. 2012: Development of a light microscopy stain for the sclerites of Gyrodactylus von Nordmann, 1832 (Monogenea) and related genera. Parasitol. Res. 110: 1639-1648.

Harris P.D., Cable J., Tinsley R.C., Lazarus C.M. 1999: Combined ribosomal DNA and morphological analysis of individual gyrodactylid monogeneans. J. Parasitol. 85: 188-191.

Héritier L., Badets M., Du Preez L. H., Aisien M. S., Lixian F., Combes C., Verneau O. 2015: Evolutionary processes involved in the diversification of chelonian and mammal polystomatid parasites (Platyhelminthes, Monogenea, Polystomatidae) revealed by palaeoecology of their hosts. Mol. Phylogenet. Evol. 92: 1-10.

Kearn G.C. 1994: Evolutionary expansion of the Monogenea. Int J. Parasitol. 24: 1227-1271.
Kearn G.C. 2004: Leeches, Lice and Lampreys. A Natural History of Skin and Gill Parasites of Fishes. Springer, Dordrecht, 446 pp.

Kearn G.C., Evans-Gowing R. 1998: Attachment and detachment of the anterior adhesive pads of the monogenean (platyhelminth) parasite Entobdella solea from the skin of the common sole (Solea solea). Int. J. Parasitol. 28: 1583-1593.

KoK D.J., Du Preez L.H. 1987: Polystoma australis (Monogenea) life-cycle studies in experimental and natural infections of normal and substitute hosts. J. Zool. Lond. 212: 235-243.

KoK D.J., Du Preez L.H. 1989: Polystoma australis (Monogenea): development and reproduction in neotenic parasites. SA J. Zool. 24: $225-230$.

Moeng I.A., Du Preez L.H. 1999: Clustering in Oculotrema hippopotami (Monogenea: Polystomatidae). Microsc. Soc. S. Afr. 29: 73.

Moeng I.A., Kruger J., Cooper S., Du Preez L.H. 1998 Unique musculature found in Oculotrema hippopotami (Monogenea: Polystomatidae). Microsc. Soc. S. Afr. 28: 83.

OzAKi Y. 1935: Morphology of the adult form with review of the family Polystomatidae. J. Sci. Hiroshima Univ. Ser.B, Div.1. 3: 139-223.

Pichelin S. 1995: The taxonomy and biology of the Polystomatidae (Monogenea) in Australian freshwater turtles (Chelidae, Pleurodira). J. Nat. Hist. 29: 1345-1381.

Pichelin S., Whittington I.D, Pearson J.C. 1991: Concinnocotyla (Monogenea: Polystomatidae), a new genus for the polystome from the Australian lungfish Neoceratodus forsteri. Syst. Parasitol. 18: 81-93.

Poulin R. 2011: Evolutionary Ecology of Parasites. Second Edition. Princeton University Press, Princeton, 342 pp.

Reichenbach-Klinke H. 1966: Eine neue Art der Polystomatidengattung Eupolystoma Kaw, 1950 (Monogenea, Polystomatidae) von den Kiemen des australischen Lungenfishes Neoceratodus forsteri Krefft. Zool. Anz. 176: 142-146.

Sproston N.G. 1946: A synopsis of the monogenetic trematodes. Trans. Zool. Soc. Lond. 25: 185-355.

Stunkard H.W. 1917: Studies on North American Polystomidae, Aspidogastridae and Paramphistomidae. Illinois Biol. Monogr. 3: 283-394.

Tinsley R.C. 1971: The adaptation for attachment by the Polystomatidae (Monogenoidea). Comptes Rendus, Premier Multicolloque Européen de Parasitologie, Rennes, 1-4 September, pp. 65-68.

Tinsley R.C., Tinsley M.C. 2016: Tracing ancient evolutionary divergence in parasites. Parasitology 143: 1902-1916.

Williams J.B. 1960: The dimorphism of Polystoma integerrimum (Frolich) Rudolphi and its bearing on relationships within the Polystomatidae. J. Helminthol. 34: 323-346.

Yamaguti S. 1963: Monogenea and Aspidocotylea. Systema Helminthum, Part IV. John Wiley and Sons Inc., New Jersey, 699 pp.

Yoon G.H., Al-Jufaili S., Freeman M.A., Bron J.E., PaladIni G., Shinn A. P. 2013: Omanicotyle heterospina n. gen. et n. comb. (Monogenea: Microcotylidae) from the gills of Argyrops spinifer (Forsskål) (Teleostei: Sparidae) from the Sea of Oman. Parasit. Vector. 6: 170 .

Cite this article as: Du Preez L. H. ,Theunissen M. 2021: A sucker for the job: morphology and functioning of suckers of polystomatid monogeneans. Folia Parasitol. 68: 006. 